
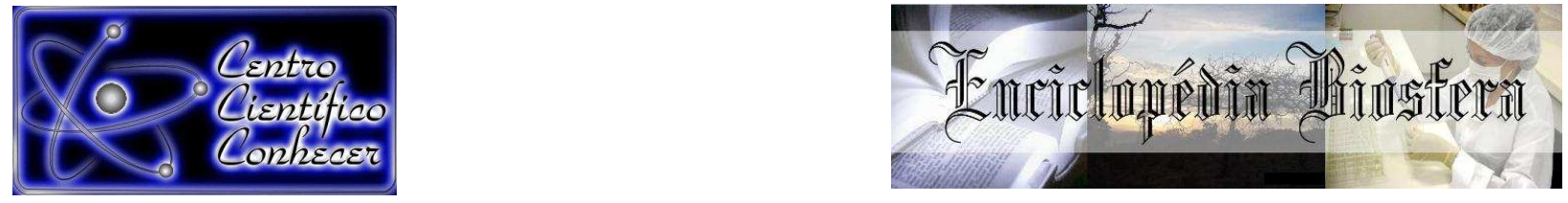

\title{
VIOLÊNCIA INTRAFAMILIAR CONTRA A CRIANÇA E REPERCUSSÕES NO CONTEXTO ESCOLAR
}

\author{
Jeferson de Souza Sá1; Andréa Grano Marques. ${ }^{2}$ \\ 1 Psicólogo e Mestrando em Promoção da Saúde do Centro Universitário de Maringá \\ - UNICESUMAR - Maringá, Paraná, Brasil. Bolsista CAPES. \\ jefersonsouzasa@gmail.com \\ 2 Profa, Dra do Programa de Mestrado em Promoção da Saúde do Centro \\ Universitário de Maringá - UNICESUMAR - Maringá, Paraná, Brasil. Pesquisadora, \\ Bolsista Produtividade em Pesquisa do Instituto Cesumar de Ciência,Tecnologia e \\ Inovação - ICETI
}

Recebido em: 02/10/2017 - Aprovado em: 21/11/2017 - Publicado em: 05/12/2017 DOI: 10.18677/EnciBio 2017B100

\begin{abstract}
RESUMO
A violência intrafamiliar que acomete crianças e adolescentes tem sido objeto de pesquisa em função do aumento do número de casos nos últimos anos, alcançando proporções epidêmicas. Este tipo de violência é caracterizado por ação ou omissão que prejudique a integridade física e/ou psicológica, assim como por negligência em relação aos cuidados básicos necessários para o desenvolvimento psicossocial infantil. A escola configura-se como ambiente favorável para a detecção de casos de maus-tratos infantis na medida que abrange significativo percentual da população infantil. Desta forma, o objetivo deste estudo foi compreender as repercussões, no contexto escolar, da violência intrafamiliar contra a criança. Esta pesquisa, de abordagem qualitativa, foi realizada por meio de revisão bibliográfica em bases de dados de artigos científicos. Os artigos foram pesquisados nas bases de dados Lilacs, Scielo e Pubmed. A violência intrafamiliar interfere diretamente no processo educacional e nas relações estabelecidas no contexto escolar, estimulando a agressividade e outros comportamentos inoportunos neste meio, podendo significar um verdadeiro reflexo do tratamento recebido no ambiente familiar. Em relação aos prejuízos cognitivos, vítimas de maus-tratos apresentam níveis de inteligência geral inferiores a outros sujeitos. Concluiu-se que compreender as relações familiares e seu reflexo no contexto escolar, permite a concepção e implementação de estratégias que envolvam a educação, a assistência e a promoção da saúde, capazes de transformar este trágico cenário que vem comprometendo a qualidade de vida, o desenvolvimento psicossocial e cognitivo de crianças vítimas de violência intrafamiliar.
\end{abstract}

PALAVRAS-CHAVE: Aprendizagem, Promoção da Saúde, Violência Doméstica 


\title{
INTRAFAMILIAL VIOLENCE AGAINST CHILDREN AND REPERCUSSIONS IN THE SCHOOL CONTEXT
}

\begin{abstract}
Intrafamily violence affecting children and adolescents has been the subject of research due to the increase in the number of cases in recent years, reaching epidemic proportions. This type of violence is characterized by an act or omission that damages the physical and / or psychological integrity, as well as by the negligence regarding the basic care necessary for the child's psychosocial development. The school is a favorable environment for the detection of cases of child maltreatment insofar as it comprises a significant percentage of the child population. Therefore, the objective of this study was to understand the repercussions, in the school context, of intrafamily violence against the child. This research, of qualitative approach, was carried out by means of bibliographical revision in databases of scientific articles. The articles were investigated in the Lilacs, Scielo and Pubmed databases. Domestic violence interferes directly in the educational process and in the relations established in the school context, stimulating aggression and other inopportune behaviors in this environment, being able to be a true reflection of the treatment received in the family environment. In terms of cognitive impairments, victims of abuse have lower intelligence levels than other subjects. The conclusion is that understanding family relationships and their reflection in the school context allows the conception and implementation of strategies that involve education, care and health promotion, capable of transforming this tragic scenario that is compromising quality of life, psychosocial and cognitive development of children victims of intrafamily violence.
\end{abstract}

KEYWORDS: Learning, Health Promotion, Domestic Violence

\section{INTRODUÇÃO}

A violência caracteriza-se como um dos problemas de saúde pública, pois causa impacto na integridade dos sujeitos que sofrem a agressão, afetando a saúde física, mental e comprometendo o bem-estar (WAISELFISZ, 2012). Segundo Brino e Souza (2016) a violência contra a criança pode gerar diversas consequências no processo de desenvolvimento, alterando a conduta e as emoções e interferindo no processo de socialização e de aprendizagem da criança.

Os dados apresentados no documento intitulado "Mapa da Violência 2012 crianças e adolescentes no Brasil" reafirmaram que a situação é preocupante no Brasil quando o assunto é violência contra a criança e o adolescente. De acordo com esse documento, o Brasil ocupa o 4ํㅣㅁ lugar no ranking de um total de 99 países monitorados pela Organização das Nações Unidas por apresentarem números elevados de homicídios praticados contra crianças e adolescentes (WAISELFISZ, 2012).

A violência infantil apresenta-se como um fenômeno social e cultural complexo, pois atingem crianças e adolescentes em diversos contextos, tanto sociais quanto familiares. A violência intrafamiliar que acomete crianças e adolescentes tem sido objeto de pesquisa em função do aumento do número de casos nos últimos anos, alcançando proporções epidêmicas (MEZZALIRA; GUZZO, 2015). Este tipo de violência compreende formas agressivas de interação dos pais 
com as crianças ou adolescentes, justificando as atitudes como sendo estratégias de educação ou de solução de conflitos (PINTO; ASSIS, 2013).

O Ministério da Saúde define a violência intrafamiliar como toda ação ou omissão que prejudique o bem-estar físico, psicológico ou a liberdade e o direito ao pleno desenvolvimento de outro membro da família sendo praticada por um ou mais autores com laços familiares, conjugais ou de parentesco, ou com vínculo afetivo em condições de relação de poder (BRASIL, 2002; MACHADO et al., 2014). Embora as consequências, para o indivíduo que sofre violência intrafamiliar, ultrapassem 0 caráter particular há uma tendência de naturalização e de ocultamento do fenômeno (SANTOS et al., 2015).

A violência infantil coloca em destaque o ambiente escolar, pois depois do ambiente familiar configura-se como o espaço de maior convívio social desses indivíduos, tornando-se um ambiente favorável para a detecção de casos onde há indícios de maus-tratos infantil (NESELLO et al., 2014). Diante disto, este estudo buscou compreender as repercussões, no contexto escolar, da violência intrafamiliar contra a criança.

Trata-se de uma revisão da literatura realizada a partir de artigos científicos. Os artigos foram pesquisados nas bases de dados Lilacs (Literatura LatinoAmericana e do Caribe em Ciências da Saúde), na biblioteca virtual da Scielo (Scientific Electronic Library Online) e Pubmed. Para a busca dos artigos foi utilizado como descritores as seguintes combinações: violência doméstica and aprendizagem e maus-tratos infantis, publicados no período de 2011 a 2017. Após a leitura procedeu-se a análise descritiva e de conteúdo. Foram incluídos os artigos relacionados ao tema da pesquisa.

\section{VIOLÊNCIA INTRAFAMILIAR CONTRA A CRIANÇA}

A violência intrafamiliar contra a criança vem ganhando espaço nas discussões sobre a saúde, educação e políticas públicas em diversos países (BRINO; SOUZA, 2016). Caracteriza-se como toda ação ou omissão que prejudique a integridade física e/ou psicológica, assim como negligência em relação aos cuidados básicos necessários para o desenvolvimento psicossocial infantil (SANTOS et al., 2015; RIBEIRO et al., 2015).

O Sistema de Informação de Agravos Notificados foi criado com o intuito de dimensionar a magnitude da violência e dos problemas de saúde no Brasil (BRASIL, 2017). Este sistema permite o registro e a padronização dos dados para o planejamento de investimentos em núcleos de vigilância e assistência, garantindo o direito de proteção e de desenvolvimento com dignidade de todas as crianças (ASSIS et al., 2012).

A partir das informações disponibilizadas pelo Sistema de Informação de Agravos Notificados (Sinan-Net) foram coletados os dados de violência contra a criança de zero a nove anos, notificados no período de 2009 a 2014 (BRASIL, 2017). A Organização Mundial de Saúde classifica a violência contra a criança em quatro tipos: abuso físico, sexual, emocional ou psicológico e negligência (WORLD HEALTH ORGANIZATION, 2006). Portanto, os resultados apresentados na tabela 1 foram agrupados de acordo com os tipos de violência infantil e respectivas frequências de notificações. 
TABELA 1. Frequência por tipo de violência sofrida por crianças de zero a nove anos no período de 2009 a 2014 no Brasil.

\begin{tabular}{llllllll}
\hline Tipos de Violência & \multicolumn{7}{c}{ Ano } \\
\hline & $\mathbf{2 0 0 9}$ & $\mathbf{2 0 1 0}$ & $\mathbf{2 0 1 1}$ & $\mathbf{2 0 1 2}$ & $\mathbf{2 0 1 3}$ & $\mathbf{2 0 1 4}$ & \\
\hline Física & 2484 & 3947 & 5502 & 8795 & 8454 & 7092 & 36274 \\
Sexual & 2541 & 4109 & 5048 & 7027 & 7651 & 5630 & 32006 \\
Psicológica & 1612 & 2491 & 3476 & 4650 & 4982 & 3677 & 20888 \\
Negligência & 2632 & 4540 & 7086 & 11672 & 14332 & 11452 & 51714 \\
Total & 9269 & 15087 & 21112 & 32114 & 35419 & 27851 & 140852 \\
\hline
\end{tabular}

Fonte: Brasil. Ministério da Saúde. Sistema de Informação de Agravos de Notificação

- Sinan Net (2017).

Pode-se observar na tabela 1 que foram notificados 51.714 casos de violência contra a criança de zero a nove anos, no período de 2009 a 2014 no país, apesar do expressivo número de casos registrados estima-se que o número seja ainda maior, pois muitos casos não são notificados. A Lei $\mathrm{n}^{\circ}$ 8.069/1990, que promulgou 0 Estatuto da Criança e do Adolescente assegurou o direito de proteção integral à criança contra qualquer forma de maus-tratos, determina penalidades para os que a praticam, além de tornar compulsória a notificação de casos suspeitos ou confirmados (BRASIL, 1990).

Em 2001, com a publicação da Política Nacional de Redução da Morbimortalidade por Acidentes e Violência na Infância e na Adolescência, foi estabelecida como obrigatória a notificação de casos suspeitos e confirmados de maus-tratos pelos profissionais dos estabelecimentos que atendem pelo Sistema Único de Saúde (BRASIL, 2001). Entretanto, apesar da obrigatoriedade, a subnotificação da violência contra a criança e adolescentes é uma realidade no Brasil, porém pesquisas e ações vêm ocorrendo no sentido de mobilizar os profissionais a lidar melhor com o tema e a realizar a notificação (SILVA et al., 2015).

Santos et al. (2015) e Pasian et al. (2015) constataram em seus estudos que hospitais, escolas e outras instituições, apresentaram resistência quanto a notificação de casos de violência contra a criança, identificando como obstáculos principais o constrangimento frente às situações de violência contra a criança e o adolescente, insegurança relacionada a abordagem do tema e dificuldades no preenchimento do cadastro de notificação.

Bannwart e Brino (2011) analisaram as dificuldades na identificação e notificação de maus-tratos contra a criança enfrentadas por pediatras e constataram que os profissionais apresentam dúvidas em relação a resolubilidade dos casos, havendo medo e insegurança emocional por parte de quem atende a criança e a família, os profissionais destacaram também a existência de lacunas em relação ao tema na formação profissional e a reprodução de padrões culturais do não envolvimento em assuntos que seriam do âmbito familiar.

A não notificação dos casos de violência infantil por parte dos profissionais da saúde e da educação ocorre pela falta de conhecimento sobre esta temática. Silva et al. (2015) afirmam que "quanto mais conscientes acerca do papel que devem desempenhar, maiores são as chances de notificarem um caso de violência contra crianças ou adolescentes". Dessa forma, torna-se necessário o treinamento dos profissionais, buscando a compreensão do fenômeno, mudanças de discursos, crenças e atitudes em relação à violência infantil.

O Programa de Vigilância e Prevenção de Violências e Acidentes do Ministério da Saúde têm capacitado os profissionais sobre a importância da ENCICLOPÉDIA BIOSFERA, Centro Científico Conhecer - Goiânia, v.14 n.26; p.1178 2017 
notificação. Como consequência dessas ações, no Brasil, o número de notificações de violência de sujeitos com até 19 anos por profissionais de saúde, mais que triplicou, passando de 18570 mil em 2009, para 67097 mil casos notificados em 2012, o que evidência que os profissionais da saúde estão mais conscientes na importância que esses registros podem promover saúde, assistência e cuidado as crianças vitimas de violência (SILVA et al., 2015).

A tabela 1 demonstra que a violência física apresentou o maior número de notificações, por ser de mais fácil detecção, pois é manifestada por diversas formas como tapas, empurrões, chutes, queimaduras, estrangulamento, lesões por armas ou objetos, deixando marcas passíveis de serem identificadas. A violência física ocorre quando uma pessoa que exerce poder sobre outra causa ou tenta causar dano não acidental, por meio do uso da força física ou de algum tipo de arma provocando lesões externas, internas ou ambas. As consequências deste tipo de violência podem ser tanto físicas quanto psicológicas (LIMA, 2013). Segundo concepções mais recentes, o castigo repetido também deve ser considerado como violência física (MACHADO et al., 2014).

De acordo com os dados apresentados na tabela 1 a violência sexual ocupa o segundo lugar em notificação. A violência sexual é toda ação na qual uma pessoa, por meio de força física, coerção ou intimidação psicológica, obriga uma outra ao ato sexual ou a interações sexuais contra a sua vontade, propiciando vitimização e gratificação ao agressor (DESLANDES et al., 2016). O abuso sexual na infância ou na adolescência caracteriza-se como a participação de criança ou de adolescente em atividades sexuais que são inapropriadas a idade e ao desenvolvimento psicossexual. A vítima é forçada fisicamente, coagida ou seduzida a participar da relação sem ter necessariamente a capacidade emocional ou cognitiva para consentir ou julgar o que está acontecendo. A interação pode envolver toques, carícias, sexo oral ou relações com penetração, genital ou anal, além de outras sem contato físico, como voyeurismo, assédio, exibicionismo, pornografia e exploração sexual (GOLDMAN; GRINBEEK, 2014).

A violência sexual pode estar associada às experiências do agressor, normalmente da experiência de abuso sexual vivenciados na infância e, principalmente, no ambiente familiar. Na maioria dos casos de abuso sexual infantil os conflitos não elaborados ou resolvidos adequadamente, pode fazer com que o sujeito recapitule o drama vivido, tornando-se futuramente um agressor ou abusador infantil (PINTO JUNIOR et al., 2015).

A violência psicológica, terceiro tipo de violência notificada, conforme tabela 1 , afeta o desenvolvimento psicológico, emocional, social e cognitivo da vítima. Pode ser compreendida como toda ação ou omissão que causa ou visa causar dano tanto para a autoestima quanto para a identidade da criança. Este tipo de violência apresenta atos verbais como insultos, gritos, palavras de desprezo e de críticas. Em crianças pode ocorrer quando os pais ou responsáveis constantemente depreciam a criança, bloqueiam seus esforços de autoaceitação e de realização, causando-lhes sofrimento psicológico (MACHADO et al., 2014). O sofrimento psíquico ocasionado por este tipo de maus-tratos pode acompanhar a vítima durante toda a sua vida, gerando profundos sentimentos de insegurança, sensação de abandono e de solidão, comprometendo a aprendizagem e o estabelecimento de novos vínculos afetivos (LIMA, 2013).

A negligência intrafamiliar contra crianças ocupa o quarto lugar entre os tipos de violência contra a criança (tabela 1). A negligência implica o não atendimento das necessidades físicas e cognitivas básicas pelos adultos com os quais a criança 
convive. Define-se pela incapacidade dos pais de suprir as necessidades de segurança, afeto, educação, alimentação e higiene e caracteriza-se como abandono em lugares desconhecidos, danos à integridade corporal decorrentes de negligência, omissão de cuidados e de proteção contra agravos evitáveis como situações de perigo, doenças, gravidez, alimentação, higiene, entre outros (MACHADO et al., 2014). A Lei $n^{\circ}$ 8.069/1990, denominada Estatuto da Criança e do Adolescente, em seu artigo $5^{\circ}$, trata da proteção de crianças e adolescentes contra a negligência, discriminação, exploração, violência, crueldade, opressão e todos os atentados, por ação ou omissão em relação aos seus direitos fundamentais (BRASIL, 1990).

Embora reconhecida como o tipo mais comum de maus-tratos cometidos contra a criança caracteriza-se como um tipo de violência de difícil detecção, por não inspirar o mesmo grau de indignação dos demais tipos e por não deixar marcas expressivas. O ambiente domiciliar é o local onde ocorrem os eventos violentos, sendo favorável para a ocorrência de agressões e abusos contra a criança (NUNES; SALES, 2016).

Para Nunes e Sales (2016) nenhum tipo de violência cometida contra a criança justifica-se, pois as condições peculiares do desenvolvimento nesta faixa etária e a extrema dependência dos pais e dos familiares torna a criança vulnerável, cujos principais autores da agressão os próprios responsáveis pelas vítimas, mãe e pai. Portanto, a violência intrafamiliar configura-se como um desafio para gestores e profissionais do ambiente escolar, pelas variadas formas de violência interpessoal: a física, sexual, psicológica, negligência e abandono (SANTOS et al., 2015).

Alguns fatores estão relacionados com a ocorrência de maus-tratos na infância, estando associado a condições socioeconômicas, escolaridade estrutura das relações familiares entre outras, como relataram Zambon et al. (2012, p. 466):

\begin{abstract}
...condições sociais desfavoráveis (pobreza, promiscuidade, rede de apoio médico e social deficitária, desemprego, condições ruins de moradia), famílias com privação econômica, relações familiares desarmônicas, pais separados, baixo nível de escolaridade dos pais, famílias nas quais os pais abusadores ou negligentes foram abusados ou negligenciados na infância, pais (ou responsáveis) usuários de substâncias psicoativas, ou portadores de outros transtornos psiquiátricos (transtornos da personalidade, depressão, psicose etc.), além dos chamados fatores de vulnerabilidade infantis, como o fato de a criança ser recém-nascida prematura, ter retardo mental, ser do gênero masculino, ser adotada, ou estar vivendo em abrigo ou sistema de detenção compulsória.
\end{abstract}

O ambiente familiar é o primeiro aprendizado social onde a criança estabelece suas relações primordiais, em função disto em outros ambientes sociais a criança acaba projetando o que vivencia em casa, através das conversas informais, comportamentos, em desenhos e atividades escolares (SILVA et al., 2014).

\begin{abstract}
...quando o ambiente familiar é marcado pela violência, onde os pais são agressivos entre si, ou mesmo com os filhos, há a predisposição para transformar a violência em algo natural, em que o apanhar passa a não simbolizar desamor, mas, sim, uma forma natural de agir, um processo de aprendizagem desenvolvido na infância (COSTA; TEIXEIRA, 2017, p.31).
\end{abstract}

Pinto e Assis (2013) afirmaram que a violência familiar pode promover agravos não somente à saúde física da criança, mas também no seu desenvolvimento psicológico, nas relações sociais e no desempenho escolar. $O$ 
impacto vai além dos problemas comportamentais e emocionais, afetando a forma como a criança se vê e como percebe o mundo, gerando efeitos que muitas vezes só irão surgir na adolescência ou na idade adulta.

Os sinais mais comuns, que a criança vítima de violência pode apresentar, além daqueles resultantes da violência física, estão relacionados com distúrbio de humor, ansiedade, distúrbios neurológicos, depressão, dificuldades escolares, além da probabilidade do sujeito de repetir a violência sofrida em outros ambientes sociais (PINTO JUNIOR et al., 2015).

Diante deste cenário profissionais da saúde e da educação, principalmente, precisam estar atentos para identificar os sinais de violência sofrida pela criança. $O$ Estatuto da Criança e do Adolescente tem como enfoque os direitos e as obrigações de todos com o cuidado e a proteção de crianças e adolescentes (BRASIL, 1990; BRINO; SOUZA, 2016; GARBIN et al., 2016). A Lei $n^{\circ} 8.069 / 1990$ tornou o envolvimento com a proteção infantil obrigatório aos profissionais da educação e da saúde, estabelecendo o dispositivo da notificação compulsória dos casos suspeitos ou confirmados com os quais tenham contato no âmbito de seu trabalho (Art. $13 \mathrm{e}$ 245), prevendo, penalidades para médicos, professores e responsáveis por estabelecimentos de saúde e educação que deixem de comunicar os casos suspeitos ou confirmados (BRASIL, 1990; SILVA et al., 2015).

\section{ESTUDOS SOBRE A VIOLÊNCIA INTRAFAMILIAR E SUAS REPERCURSSÕES NO AMBIENTE ESCOLAR}

A compreensão da violência intrafamiliar configura-se como um desafio para os gestores e os profissionais que atuam no campo da educação, pois é preciso considerar as várias formas de violência que crianças ou adolescentes podem estar submetidos, como a violência física, a sexual e a psicológica que inclui negligência e abandono (SANTOS et al., 2015).

A escola é uma instituição de extrema importância para a criança, tanto pelo papel de ensinar quanto pelo potencial para a construção de estratégias de enfrentamento da violência (CARLOS et al., 2014), pois a escola configura-se como ambiente favorável para a detecção de casos de maus-tratos infantis na medida que abrange significativo percentual da população infantil. Neste ambiente, as crianças passam muitas horas por dia, convivendo com professores e outros profissionais, o que facilita a apreensão de indicadores de violência contra a criança, incluindo os de negligência, que servem de alerta à identificação de casos de maus-tratos infantil (PASIAN et al., 2015).

Segundo Costa et al. (2013) o ambiente familiar influencia o comportamento que a criança expressa no ambiente escolar. Freitas et al. (2015) afirmaram que as crianças e os adolescentes que testemunham a violência ou que são agredidos por seus familiares tendem a apresentar comportamentos agressivos e antissociais fora de casa, principalmente na escola. "Os padrões aprendidos pelos filhos tendem a se repetir, uma vez que a violência passa a ser a principal forma de mediar as relações sociais entre os membros dessas famílias" (COSTA; TEIXEIRA, 2017, p.27).

Contrariando as expectativas sociais em relação ao papel de proteção que o núcleo familiar deveria desempenhar, muitas famílias apresentam-se como cenários de violência para inúmeras crianças e adolescentes. São consideradas vítimas tanto sujeitos que sofrem 0 abuso quanto crianças e adolescentes que testemunham situações de abuso, principalmente de um progenitor ao outro. Preto e Moreira (2012) investigaram o aprendizado de crianças e relataram que os filhos de mulheres vítimas de violência doméstica obtiveram rendimento escolar inferior ao 
dos filhos de mulheres não vítimas, confirmando que a violência intrafamiliar é um fator gerador de déficit no desenvolvimento da criança.

É notório que crianças vitimizadas apresentam dificuldade de atenção e aprendizagem, assim como problemas de comportamento (RIBEIRO et al., 2015). Wang et al. (2016) analisaram 1.284 crianças de três a seis anos na área urbana de Lanzhou, China, e afirmaram que crianças vítimas de algum tipo de violência apresentaram maior taxa de problemas comportamentais quando comparadas àquelas que não foram expostas a atos violentos. Desta forma, os problemas comportamentais em crianças pré-escolares foram correlacionados com a violência intrafamiliar. Os autores afirmaram que durante o processo de crescimento de préescolares a violência intrafamiliar pode gerar diversos agravos no desenvolvimento mental das crianças.

Os efeitos da violência doméstica sobre o comportamento disciplinar e sobre o desempenho acadêmico de alunos vítimas de violência intrafamiliar foram relatados por professores na investigação realizada por Ristum (2014). Quanto ao aspecto disciplinar o autor relatou comportamentos agressivos, desobediência, dificuldade de relacionamento, tendência ao isolamento ou agitação e, quanto ao aspecto acadêmico foi descrito que a maioria possui baixo rendimento escolar, dificuldade de aprendizagem, desinteresse e desatenção. Outros comportamentos que podem indicar violência no âmbito familiar foram citados como relacionamento frio e distante com os colegas, não conversar e não brincar, timidez, introversão, retraimento e distanciamento do convívio.

Outro aspecto que deve ser considerado é que a agressividade de crianças vítimas de maus-tratos familiar no contexto escolar causa rejeição por parte dos colegas e dos professores, aumentando o descontrole emocional e afetando os processos de aprendizagem (ALMEIDA et al., 2013). A pesquisa feita por Silva (2014) investigou os efeitos da violência intrafamiliar sobre as relações interpessoais em sala de aula e os resultados indicaram que a violência em sala de aula é reflexo da violência intrafamiliar influenciando negativamente o desempenho escolar das crianças. As famílias, por sua vez, responsabilizam a escola pelos atos de violência cometidos por seus filhos. Porém, os alunos que apresentam comportamento agressivo na escola relataram que sofrem violência física e/ou psicológica em casa por seus pais ou parentes, o que os deixam revoltados e estimulados a praticar atos desagradáveis no ambiente escolar. Portanto, o comportamento agressivo de pais ou responsáveis interfere diretamente no processo educacional de seus filhos sendo projetado em sala de aula, estimulando a agressividade da criança tornando-a impaciente e revoltada (SILVA, 2014).

A violência familiar pode ser detectada em escolas a partir de alguns indicadores: ausência frequente do aluno, baixo rendimento, falta de atenção e de concentração e comportamentos como apatia, passividade, agressividade e choro (LIMA, 2013). As crianças de forma inconsciente tendem a dar sinais de que estão vivenciando algum tipo de violência em seu meio familiar. Ristum (2014) investigou como os professores identificam a violência intrafamiliar e relatou que as crianças possuem diversas formas de demonstrar que são vítimas ou que presenciam a violência familiar, desde marcas ou ferimentos no corpo e comportamentos agressivos ou isolamento e retraimento, até sinais mais sutis como a projeção dos conflitos familiares nos desenhos e no brincar.

O estudo realizado por Garbin et al. (2016), com 91 professores de 13 Escolas Municipais de Ensino Básico, identificou 272 casos de violência infantil (de um total de 879 crianças) no ano letivo de 2015. Sendo a negligência $(92,6 \%)$ a 
principal forma de violência encontrada, seguida da violência física $(3,7 \%)$, violência sexual $(2,6 \%)$ e violência psicológica $(1,1 \%)$. Do total de agressões, $51,1 \%$ foram identificadas em crianças do sexo masculino e 48,9\% em crianças do sexo feminino. Os sinais de negligência descritos no estudo de Garbin et al. (2016) são apresentados na tabela 2 .

TABELA 2: Distribuição de frequências e porcentagens dos sinais e sintomas de violência identificados pelos educadores.

\begin{tabular}{lll}
\hline SINAIS E SINTOMAS DE VIOLÊNCIA & Frequência & Porcentagem(\%) \\
\hline Negligência & $(\mathrm{N}=252)$ & \\
Presença de piolho & 96 & $35,3 \%$ \\
Agressividade & 43 & $15,8 \%$ \\
Roupa inadequada & 42 & $15,4 \%$ \\
Cárie & 30 & $11 \%$ \\
Isolamento & 16 & $5,9 \%$ \\
Doença sem busca por tratamento & 12 & $4,4 \%$ \\
Falta de higiene pessoal & 5 & $1,8 \%$ \\
Hiperatividade & 3 & $1,1 \%$ \\
Dificuldade de aprendizagem & 3 & $1,1 \%$ \\
Carência afetiva & 2 & $0,7 \%$ \\
Violência física & $(\mathrm{N}=10)$ & \\
Marcas de agressão física & 10 & $3,8 \%$ \\
Violência sexual & $(\mathrm{N}=7)$ & \\
Comportamento sexualizado & 7 & $2,6 \%$ \\
Violência psicológica & $(\mathrm{N}=3)$ & \\
Agressão verbal & 3 & $1,1 \%$ \\
\hline
\end{tabular}

Fonte: Garbin et al. (2016)

A tabela 2 aponta os sinais e sintomas da violência infantil mais frequentemente identificados pelos educadores no estudo de Garbin et al. (2016). Os dados permitem observar que os aspectos negligenciados comprometem a saúde física e mental. Investigação realizada por Pinto Jr et al., (2015) também descreveram a prevalência de omissões familiares nos cuidados com a saúde e a educação de crianças, além do abandono. O abandono parcial está relacionado com a privação de afeto que resulta em carência afetiva, e também ao atendimento das necessidades básicas da criança.

Segundo Jackson et al. (2015) as consequências de maus-tratos infantil podem ser consideradas um grave problema para o indivíduo, a família e a sociedade. $\mathrm{O}$ abuso infantil e a negligência podem causar mudanças hereditárias permanentes na resposta do organismo ao estresse, que por sua vez inflige mudanças profundas no cérebro em desenvolvimento. Embora essas mudanças permitem que uma criança consiga conviver em um ambiente negligente, caótico e até mesmo violento, isso pode influenciar fortemente 0 funcionamento comportamental, cognitivo, físico e mental, assim como o seu bem-estar ao longo da vida.

Os maus-tratos infantis podem gerar diversos resultados negativos para o desenvolvimento da criança no contexto escolar, como: evasão escolar, problemas de comportamento na escola, menor desempenho escolar, dificuldades em estabelecer amizades, problemas de aprendizagem em decorrência de fatores emocionais, transferência da agressividade vivenciada em casa para o ambiente 
escolar, dentre outros aspectos (PATIAS et al., 2014). O baixo rendimento escolar deve ser atribuído não só às características individuais da criança, mas também ao seu contexto familiar, escolar e social no qual a criança está inserida (LIMA, 2013).

Os problemas relacionados às questões pedagógicas da criança vítima de maus-tratos estão relacionados às seguintes dificuldades: expressão oral, emitir as próprias opiniões de forma verbal ou escrita, resolução de problemas, raciocínio lógico matemático, interpretação de textos com conceitos subjetivos, produção de textos organizados com uma sequência de fatos e coerência (LIMA, 2013).

Gava et al. (2013) e Moura et al. (2014) afirmaram em suas pesquisas que as possíveis alterações advindas da violência intrafamiliar estão relacionadas com ansiedade, sintomas depressivos, culpa, vergonha, ódio, medo, raiva, ideação e comportamentos suicidas, baixa autoestima, comportamentos agressivo e regressivo, isolamento social, comportamento sexual inadequado à faixa etária, furtos, fugas do lar, prejuízo no desempenho escolar, alterações do apetite, dentre outros.

Pesquisa realizada por Bruce et al. (2013) evidenciou a associação entre maus-tratos e presença de sintomatologia ansiosa. Crianças que sofreram violência apresentam uma maior vulnerabilidade a diversos transtornos de ansiedade ao longo da vida, incluindo agorafobia, transtorno do pânico, fobias específicas e fobia social. $O$ tipo de abuso ou de negligência sofrido também impacta no tratamento ao transtorno de ansiedade, sendo que crianças que sofreram abuso sexual ou emocional apresentam maior sintomatologia de ansiedade social e dificuldades em aderir um tratamento adequado.

A meta-análise realizada por Nanni et al. (2012) encontra associação significativa entre maus-tratos na infância e risco elevado para episódios depressivos recorrentes ao longo da vida. O estudo demonstrou, ainda, que pessoas que sofreram maus-tratos na infância apresentaram pior prognóstico no tratamento para depressão, apresentando falta de resposta a terapia. Isto indica que os maus-tratos na infância podem gerar tanto uma maior vulnerabilidade à depressão quanto uma menor capacidade do paciente de estabelecer vínculo terapêutico e ter resultados positivos ao longo do processo terapêutico, gerando efeitos de longo prazo bastante deletérios para o indivíduo.

Os alunos que presenciam ou sofrem a violência no ambiente familiar podem apresentar interferência em seu desenvolvimento emocional e comportamental, o que influencia na aprendizagem. Nesse contexto, é de suma importância retratar que a timidez e a apatia também foram citadas por professores como indicativos de que a criança está tendo algum tipo de problema familiar (RISTUM, 2014).

Bazon e Faleiros (2013) consideraram que os educadores/professores estão bem posicionados para a identificação de uma ampla gama de casos de maustratos, devido ao fato de conviverem diariamente e entrarem em contato com um grande número de crianças, em diferentes atividades. Os educadores são capazes de observar mudanças de comportamentos e sinais físicos que funcionam como indicadores dos maus-tratos e, muitas vezes, também obtêm relatos infantis explícitos. Por essas razões, em muitos países, os profissionais da educação passaram a ser concebidos como atores fundamentais no sistema de proteção infantil.

Em relação aos prejuízos cognitivos, vítimas de maus-tratos apresentam níveis de inteligência geral inferiores a outros sujeitos. Prejuízos intelectuais em vítimas de maus-tratos trazem sérias consequências, tendo em vista que há evidência de que as questões cognitivas é o principal preditor do rendimento 
acadêmico e laboral ao longo da vida. O prejuízo na inteligência representa menor capacidade de lidar com eventos traumáticos, pois, crianças com menor capacidade intelectual apresentam dificuldades de socialização, tais como habilidades em pedir ajuda ou solicitar atenção positiva de forma adequada (DAVIS et al., 2015).

Diante desta problemática, os profissionais da área educacional podem contribuir de forma efetiva para a intervenção em casos de maus-tratos infantis, fazendo as notificações e estando cientes da obrigatoriedade desse ato, para que possam ser tomadas as medidas necessárias considerando as especificidades de cada caso. No entanto, é necessário que esses profissionais recebam treinamento adequado para identificar e notificar a violência contra a criança (PASIAN et al., 2015).

Lolli et al. (2012) afirmaram que pesquisas em diversos países tem pontuado a necessidade de educação continuada para profissionais da área de assistência à saúde, educação e social, relacionada ao reconhecimento e relato de sinais e sintomas de violência infantil. Os educadores ainda mantêm uma posição de desinformação, indiferença, negação e temor em relação ao problema da violência contra a criança.

A violência intrafamiliar interfere diretamente no processo educacional e nas relações estabelecidas no contexto escolar, estimulando a agressividade e outros comportamentos inoportunos neste meio, podendo significar um verdadeiro reflexo do tratamento recebido no ambiente familiar. Os profissionais da área de educação, devem estar atentos, sensibilizados e capacitados para identificar e atuar ao menor sinal dado pelas crianças (RISTUM, 2014).

\section{CONSIDERAÇÕES FINAIS}

Conclui-se que as pesquisas vêm identificando e avaliando as consequências da violência intrafamiliar no desenvolvimento da criança, porém ainda há poucos estudos que retratam o reflexo da violência intrafamiliar no aprendizado da criança. A escola, apesar de ocupar um lugar privilegiado na vida de crianças e adolescentes, não assume integralmente seu papel de instituição protetora da infância e adolescência.

Compreender as relações familiares e seu reflexo no contexto escolar, permite a concepção e implementação de estratégias que envolvam a educação, a assistência e a promoção da saúde, capazes de transformar este trágico cenário que vem comprometendo a qualidade de vida, o desenvolvimento psicossocial e cognitivo de crianças vítimas de violência intrafamiliar.

\section{REFERÊNCIAS}

ALMEIDA, A. A.; MIRANDA, O. B.; LOURENÇO, L. M. Violência doméstica/intrafamiliar contra crianças e adolescentes: uma revisão bibliométrica. Revista Interinstitucional de Psicologia, v.6, n.2, p.298-311, 2013. Disponível em: < http://pepsic.bvsalud.org/pdf/gerais/v6n2/v6n2a11.pdf>

ASSIS, S. G.; AVANCI, J. Q.; PESCE, R. P.; PIRES, T. O.; GOMES, D. L. Notificações de violência doméstica, sexual e outras violências contra crianças no Brasil. Ciência \& Saúde Coletiva, v. 17, n. 9, p. 2305-2317, 2012. Disponível em: $<$ www.redalyc.org/pdf/630/63023703007.pdf>

BANNWART, T. H.; BRINO, R. F. Dificuldades enfrentadas para identificar e notificar 
casos de maus-tratos contra crianças e/ou adolescentes sob a óptica de médicos pediatras. Revista Paulista de Pediatria, v. 29, n.2, p. 138-45, 2011. Disponível em: < http://www.scielo.br/pdf/rpp/v29n2/a02v29n2.pdf>

BAZON, M. R. FALEIROS, J. M. Identificação e Notificação dos Maus-tratos Infantis no Setor Educacional. Paidéia, v. 23, n. 54, p. 53-61. 2013. DOI: http://dx.doi.org/10.1590/1982-4327235422805201307

BRASIL. Ministério da Saúde. Secretaria de Políticas de Saúde. Violência intrafamiliar: orientações para prática em serviço. Brasília, 2002. Disponível em: <http://bvsms.saude.gov.br/bvs/publicacoes/cd05_19.pdf>

BRASIL, Lei $n^{\circ}$ 8.069, de 13 de Julho de 1990. Estatuto da Criança e do Adolescente. Brasília, ed. 9, 2012. Disponível em: $<$ www.crianca.mppr.mp.br/arquivos/File/publi/camara/estatuto_crianca_adolescente_ 9ed.pdf>

BRASIL, Portaria MS/GM no 737, de 16 de maio de 2001. Política Nacional de Redução da Morbimortalidade por Acidentes e Violências. Trata da responsabilidade do Gestor Municipal na redução da morbimortalidade. Diário Oficial da União, Brasília, 2001. Disponível em: < https://www.nescon.medicina.ufmg.br/biblioteca/imagem/2076.pdf>

BRASIL, Ministério da Saúde. Sistema de Informação de Agravos de Notificação SINAN. Violência Doméstica, Sexual e/ou outras violências - Notificações Registradas: banco de dados. Brasília, 2017. Disponível em: $<$ http://datasus.saude.gov.br/>

BRINO, R. F.; SOUZA, M. A. O. Concepções sobre Violência Intrafamiliar na área Educacional. Educação \& Realidade, Porto Alegre, v. 41, n. 4, p. 1251-1273, out./dez. 2016. DOI: http://dx.doi.org/10.1590/2175-623653298

BRUCE, L. C., HEIMBERG, R. G., GOLDIN, P. R., \& GROSS, J. J. Childhood Maltreatment and Response to Cognitive Behavioral Therapy Among Individuals with Social Anxiety Disorder. Depression and anxiety, v. 30, n. 7, p. 1- 8, 2013. DOI: 10.1002/da.22112

CARLOS, D. M.; FERRIANI, M. G. C.; ESTEVES, M. R.; SILVA, L. M. P.; SCATENA, L. O apoio social sob a ótica de adolescentes vítimas de violência doméstica. Revista Escola de Enfermagem da USP, v. 48, n.4, p.610-617, $2014 . \quad$ DOI: 10.1590/S0080-623420140000400006

COSTA, A. L.; TEIXEIRA, K. M. D. O Comportamento dos Alunos na Escola e Sua Relação Com a Violência Doméstica na Percepção dos Educadores. Revista Brasileira de Economia Doméstica, v. 28, n.1, p. 22-42, 2017. Disponível em: < http://www.seer.ufv.br/seer/oikos/index.php/httpwwwseerufvbrseeroikos/article/view/2 $61 / 238>$

COSTA, B. L.; FREITAS, R. F.; SANTOS, G. S.; REIS, V. M. C. P.; OGANDO, B. M. A. P.; ROCHA, J. S. B. Agressividade de crianças inseridas no projeto nadar, de 
acordo com gênero, raça, atividades em tempo livre e comportamento dos pais.

Pensar a Prática, Goiânia, v. 16, n. 4, p. 1159-1175, 2013 DOI: https://doi.org/10.5216/rpp.v16i4.21596

DAVIS, A. S., MOSS, L. E., NOGIN, M. M., WEBB, N. E. Neuropsychology of Child Maltreatment and Implications for School Psychologists. Psychology in the schools, v. 52, n.1, p. 77-91, 2015. DOI:10.1002/pits.21806

DESLANDES, S. F.; VIEIRA,L. J. E. S.; CAVALCANTI, L. F.; SILVA, R. M. Atendimento à saúde de crianças e adolescentes em situação de violência sexual, em quatro capitais brasileiras. Interface, v. 20 n.59, p. 865-77, 2016. DOI: 10.1590/1807-57622015.0405

FREITAS, R. F.; FERNANDES, B. V. M.; FREITAS, T. F.; CANTUÁRIA, V. L.; DEMASCENO, R. F.; LESSA, A. C. Consequências Físicas e Psicológicas da Violência Doméstica para a Saúde da Mulher e Para a Vida Escolar dos Filhos. Revista Desenvolvimento Social, v. 16, n.01, 2015. Disponível em: <http://www.rds.unimontes.br/index.php/desenv_social/article/view/215/154>

GARBIN, C. A. S.; ARAÚJO, P. C.; ROVIDA, T. A. S.; ROCHA, A. C.; ARCIERI, R. M.; GARBIN, A. J. I. Violência na População Infantil: Perfil Epidemiológico dos Abusos Verificados no Ambiente Escolar. Revista Ciência Plural, v. 2, n.2, p.41-54, 2016. Disponível em: <https://periodicos.ufrn.br/rcp/article/view/10122/7844>

GAVA, L. L.; SILVA, D. G.; DELL'AGLIO, D. D. Sintomas e Quadros Psicopatológicos Identificados nas Perícias em Situações de Abuso Sexual InfantoJuvenil. Revista Psico, v. 44, n. 2, p. 235-244, 2013. Disponível em: <http://revistaseletronicas.pucrs.br/ojs/index.php/revistapsico/article/view/11467/9642

GOLDEMAN, J. D. G.; GRIMBEEK, P. Child Sexual Abuse and Mandatory Reporting Intervention Preservice Content Preferred by Student Teachers. Journal of Child Sexual Abuse, v. 23, 2014. DOI: http://dx.doi.org/10.1080/10538712.2014.859200

JACKSON, A. M.; KISSOON, N.; GREENE, C. Aspects of Abuse: Recognizing and Responding to Child Maltreatment. Current Problems Pediatric Adolescent Health Care, v. 45, p. 58-70, 2015. DOI: 10.1016/j.cppeds.2015.02.001

LIMA, J. O. Violência doméstica: influência no desenvolvimento biopsicossocial e no processo de aprendizagem de quem a sofre. Interletras, v. 3, n. 18, 2013. Disponível em:

http://www.interletras.com.br/ed_anteriores/n19/artigos.php?edicao=18>

LOLLI, H. A.; LOLLI, M. C. G. S.; LOLLI, L. F.; SILVA, D. R. "Olhos De Lince" No Ambiente Escolar - A Responsabilidade Do Educador Físico Na Detecção E Encaminhamento De Casos De Violência Doméstica Contra Crianças E Adolescentes. UNINGÁ Review, v. 12, n. 2. p. 32-41, 2012. Disponível em: <http://web.a.ebscohost.com/ehost/pdfviewer/pdfviewer?vid=1\&sid=daefc7c3-77054dc1-aae1-bdcdb7be8e10\%40sessionmgr4009> 
MACHADO, J. C.; RODRIGUES, V. P.; VILELA, A. B. A.; SOMÕES, A. V.; MORAIS, R. L. G. L.; ROCHA, E. N. Violência intrafamiliar e as estratégias de atuação da equipe de Saúde da Família. Saúde e Sociedade, v.23, n.3, p.828-840, 2014. DOI $10.1590 /$ S0104-12902014000300008

MEZZALIRA, A. S. C.; GUZZO, R. S. L. The Educator and Violent Situations Experience by Student: Coping Strategies. Estudos de Psicologia, v. 32 n.1, p. 3747, 2015. DOI: http://dx.doi.org/10.1590/0103-166X2015000100004

MOURA, J. P.; ALMEIDA, J. L. S.; ARAÚJO, J. P.; MENEZES, R. M. P.; CHAVES, A. E. P. Implicações da Violência na Infância e Adolescência. Revista da Universidade Vale do Rio Verde, v. 12, n. 1, p. 513-524, $2014 . \quad$ DOI: http://dx.doi.org/10.5892/ruvrd.v12i1.1415

NANNI, V.; UHER, R.; DANESE, A. Childhood Maltreatment Predicts Unfavorable Course of Illness and Treatment out Come in Depression: a meta- nalysis. American Journal of Psychiatry, v. 169, n. 2, p. 141-151, 2012. DOI:10.1176/appi.ajp.2011.11020335

NESELLO, F.; SANT'ANNA, F. L. SANTOS, H. G. ANDRADE, S. M.; MESAS, A. E.; GONZÁLEZ, A. D. Características da violência escolar no Brasil: revisão sistemática de estudos quantitativos. Revista Brasileira de Saúde Materno Infantil, v. 14, n. 2, p. 119-136, 2014. DOI: http://dx.doi.org/10.1590/S1519-38292014000200002

NUNES, A. J.; SALES, M. C. V. Violência Contra Crianças no Cenário Brasileiro. Ciência \& Saúde Coletiva, v. 21, n. 3, p. 871-880, 2016. Disponível em: <http://www.scielo.br/pdf/csc/v21 n3/1413-8123-csc-21-03-0871.pdf>

PASIAN, M. S.; BAZON, M. R.; PASIAN, S. R.; LACHARITE, C. Negligência Infantil a Partir do Child Neglect Index Aplicado no Brasil. Psicologia Reflexão e Crítica, v. 28, n. 1, p. 106-115, 2015. DOI: 10.1590/1678-7153.201528112

PATIAS, N. D.; BOSSI, T. J.; DELL'AGLIO, D. D. Repercussões da exposição à violência conjugalnas características emocionais dos filhos: revisão sistemática da literatura. Temas em Psicologia, v.22, n.4, p. 901-915, 2014. DOI: http://dx.doi.org/10.9788/TP2014.4-17

PINTO, L. W.; ASSIS, S. G. Violência Familiar e Comunitária em Escolares do Município de são Gonçalo, Rio de Janeiro, Brasil. Revista Brasileira de Epidemiologia, v. 12, n. 2, p. 288-300, 2013. Disponível em: <http://www.scielo.br/pdf/rbepid/v16n2/1415-790X-rbepid-16-02-00288.pdf>

PINTO JUNIOR, A. A.; CASSEPP-BORGES, V.; SANTOS, J. G. Caracterização da violência doméstica contra crianças e adolescentes e as estratégias interventivas em um município do Estado do Rio de Janeiro, Brasil. Cadernos de Saúde Coletiva, v. 23, n. 2, p. 124-131, 2015. DOI: 10.1590/1414-462X201500020062 
PRETO, M.; MOREIRA. P. A. S. Autorregulação da aprendizagem em crianças e adolescentes filhos de vítimas de violência doméstica contra mulheres. Psicologia: Reflexão e Crítica, v. 2 n. 4, p. 730-737, 2012. DOI: http://dx.doi.org/10.1590/S010279722012000400012

RIBEIRO, I.M.; RIBEIRO, A.S.; PRATESI, R.; GANDOLF, L. Prevalência das várias formas de violência entre escolares. Acta Paulista de Enfermagem, v. 28, n. 1, p. 54-9, 2015. DOI: http://dx.doi.org/10.1590/1982-0194201500010

RISTUM, M. As marcas da violência doméstica e a identificação por professor do ensino fundamental. Revista Brasileira de Psicologia, v. 1, n. 1, p. 3-12, 2014. Disponível em: <http://revpsi.org/wp-content/uploads/2014/01/ristum2014>

SANTOS, A.C.; SANTOS, M. L. M.; NASCIMENTO, D. D. G. Violência Intrafamiliar: caminhos para o enfrentamento na saúde pública. Saúde em Redes, v. 1 n. 2, p. 21 30, 2015. DOI: http://dx.doi.org/10.18310\%2F2446-4813.2015v1n2p21-30

SILVA, M. R. P. Os Efeitos da Violência Intrafamiliar Sobre as Relações Interpessoais em Sala de Aula. Estação Científica, v. 4, n. 1, p. 79-95, 2014. Disponível em: <https://periodicos.unifap.br/index.php/estacao/article/view/1468/mariav4n1.pdf>

SILVA, D. I.; MAFTUM, M. A.; MAZZA, V. A. Vulnerabilidade no desenvolvimento da criança: influência dos elos familiares fracos, dependência química e violência doméstica. Texto \& Contexto - Enfermagem, v. 23, n. 4, p. 1087-94, 2014. DOI: http://dx.doi.org/10.1590/0104-07072014001700013

SILVA, P. A.; LUNARDI, V. L.; RIBEIRO, J. P.; NETTO OLIVEIRA, A. M.; VASQUEZ, T. C. S. Notificação da violência intrafamiliar contra crianças e adolescentes por profissionais de saúde no Brasil. Avances em Enfermería, v.33, n.1, 2015. DOI: http://dx.doi.org/10.15446/av.enferm.v33n1.40585

ZAMBON, M. P.; JACINTO, A. C. A.; MEDEIROS, M. M.; GUGLIELMINETTI, R.; MARMO, D. B. Violência doméstica contra crianças e adolescentes: um desafio. Revista da Associação Médica Brasileira, v. 58, n. 4, p.465-471, 2012. DOI: http://dx.doi.org/10.1590/S0104-42302012000400018

WANG, Y.; XUE, H.; CHEN, Q. Effects of family cohesion and adaptability on behavior al problems in preschool children. Chinese Journal Of Contemporary Pediatrics, v.18, n. 5, p.421-425, 2016. DOI: 10.7499/j.issn.1008-8830.2016.05.009

WAISELFISZ, J. J. Mapa da Violência 2012: crianças e adolescentes do Brasil. Brasília, $2012 . \quad$ Disponível em: <http://www.mapadaviolencia.org.br/pdf2012/MapaViolencia2012_Criancas_e_Adole scentes.pdf>

WHO - World Health Organization. Preventing child maltreatment: a guide to taking action and generating evidence. Geneva: WHO; 2006. 